"FIFA 11 for Health" for Europe in the Faroe Islands

Effects on health markers and physical fitness in 10- to 12-year-old schoolchildren

Skoradal, M-B; Purkhús, Elisabeth; Steinholm, Hildigunn; Olsen, M H; Ørntoft, Christina Øyangen; Larsen, Malte Nejst; Dvorak, J; Mohr, Magni; Krustrup, Peter

Published in:

Scandinavian Journal of Medicine \& Science in Sports

DOI:

10.1111/sms.13209

Publication date:

2018

Document version

Publisher's PDF, also known as Version of record

Document license:

CC BY

Citation for published version (APA):

Skoradal, M-B., Purkhús, E., Steinholm, H., Olsen, M. H., Ørntoft, C. Ø., Larsen, M. N., Dvorak, J., Mohr, M., \& Krustrup, P. (2018). "FIFA 11 for Health" for Europe in the Faroe Islands: Effects on health markers and physical fitness in 10- to 12-year-old schoolchildren. Scandinavian Journal of Medicine \& Science in Sports, 28(Suppl. 1), 8-17. https://doi.org/10.1111/sms.13209 


\title{
"FIFA 11 for Health" for Europe in the Faroe Islands: Effects on health markers and physical fitness in 10- to 12-year-old schoolchildren
}

\author{
M.-B. Skoradal ${ }^{1}$ \\ E. Purkhús ${ }^{1}$ \\ H. Steinholm 1 \\ M. H. Olsen ${ }^{1}$ \\ C. Ørntoft ${ }^{2}$ \\ M. N. Larsen ${ }^{2,3}$ \\ J. Dvorak ${ }^{4}$ \\ M. Mohr ${ }^{1,2,5}$ \\ P. Krustrup ${ }^{2,6}$
}

${ }^{1}$ Faculty of Health Sciences, Centre of Health Science, University of the Faroe Islands, Tórshavn, Faroe Islands

${ }^{2}$ University of Southern Denmark, Department of Sports Science and Clinical Biomechanics, Odense, Denmark

${ }^{3}$ University of Copenhagen, Copenhagen, Denmark

${ }^{4}$ Schulthess Klinik, Zurich, Switzerland

${ }^{5}$ Center for Health and Performance, Department of Food and Nutrition, and Sport Science, University of Gothenburg, Gothenburg, Sweden

${ }^{6}$ Sport and Health Sciences, College of Life and Environmental Sciences, St Luke's Campus, University of Exeter, Exeter, UK

\section{Correspondence}

Peter Krustrup, Faculty of Health Sciences, Department of Sports Science and Clinical Biomechanics, University of Southern Denmark, Odense, Denmark.

Email: pkrustrup@health.sdu.dk

\section{Funding information}

Danish Football Association; Faroese Board of Public Health; Faroese Football Federation; FIFA Medical Assessment and Research Centre (F-MARC)
We evaluated effects of the school-based intervention "FIFA 11 for Health" for Europe on health and fitness profile in 10- to 12-year-old Faroese schoolchildren. 392 fifth-grade children were randomized into a control group (CG: $n=100$, $11.1 \pm 0.3$ years, $149.0 \pm 6.7 \mathrm{~cm}, 42.4 \pm 10.2 \mathrm{~kg}$ ) and an intervention group (IG: $\mathrm{n}=292,11.1 \pm 0.3$ years, $150.6 \pm 6.9 \mathrm{~cm}, 44.2 \pm 9.4 \mathrm{~kg}$ ). IG underwent an 11week intervention in which 2 weekly sessions of 45 minutes were included in the school curriculum focusing on health aspects, football skills, and 3v3 small-sided games. CG continued with their regular activities. Body composition, blood pressure, and resting heart rate, as well as Yo-Yo intermittent recovery children's test (YYIR1C) performance, horizontal jumping ability and postural balance were assessed pre and post intervention. Systolic blood pressure decreased more $(-2.8 \pm 9.9$ vs $2.9 \pm 8.4 \mathrm{~mm} \mathrm{Hg}, P<.05)$ in IG than in CG. Lean body mass $(1.0 \pm 1.7$ vs $0.7 \pm 1.6 \mathrm{~kg})$, postural balance $(0.3 \pm 3.9$ vs $-1.2 \pm 5.9$ seconds $)$ and horizontal jump performance $(5 \pm 9 \mathrm{vs}-5 \pm 10 \mathrm{~cm})$ increased more $(P<.05)$ in IG than in CG. YYIR1C performance improved in CG $(17 \%, 625 \pm 423$ to $730 \pm 565 \mathrm{~m})$ and IG $(18 \%, 689 \pm 412$ vs $813 \pm 391 \mathrm{~m})$, but without between-group differences. A withingroup decrease from $23.1 \pm 8.4$ to $22.5 \pm 8.3 \%(P<.05)$ was observed in body fat percentage in IG only. In conclusion, the "FIFA 11 for Health" for Europe program had beneficial effects on SBP, body composition, jump performance and postural balance in 10- to 12-year-old Faroese schoolchildren, supporting the notion that school-based football interventions can facilitate health of children in a small-scale society and serve as an early step in the prevention of non-communicable diseases.

\section{K E Y W O R D S}

blood pressure, body composition, football, health education, postural balance, Yo-Yo IR1C performance

\section{1 | INTRODUCTION}

The World Health Organization (WHO) suggests that by 2030 deaths from non-communicable diseases (NCD) would have risen markedly globally to be the number one cause of death. ${ }^{1}$ Examples of high-prevalence NCDs are type 2 diabetes, obesity and cardiovascular disease (CVD) which are also partly interconnected. For example, obesity is associated with several diseases such as CVD, stroke, hypertension, type 2 diabetes, osteoporosis, and cancer. ${ }^{2,3}$ Childhood obesity is 
primarily caused by a lack of physical activity combined with an unhealthy and high energy diet, ${ }^{3}$ and being obese during childhood can increase the risks of developing NCDs in adult life. ${ }^{4-7}$ In addition, living location and gender may have a significant influence on the physical health of children due to differences in eating habits, amount of physical activity and access to sports facilities. ${ }^{8}$

Six major risk factors for developing CVD have been highlighted in previous school sport studies, that is, resting blood pressure, body fat percentage, aerobic fitness, triglycerides, cholesterol, and plasma insulin. ${ }^{4-7,9}$ In this study, 3 of these 6 major CVD risk factors were investigated (resting blood pressure, body fat percentage, and aerobic fitness). It has been shown that regular physical activity can reduce the risk of developing overweight, $\mathrm{CVD}$, and type 2 diabetes. ${ }^{1,10}$ When it comes to sport, team sports such as football are extremely popular, and studies have demonstrated beneficial effects of regular team-sport participation on health profile and CVD risk in children, including positive alterations in blood pressure and aerobic fitness, ${ }^{11-13}$ as well as body fat percentage, blood lipids and plasma insulin in some ${ }^{14}$ but not all studies. ${ }^{15,16}$ As team sports have been shown to induce broad-spectrum physical benefits in children, ${ }^{12,13,15,16}$ it is essential to use fitness assessments representing endurance, strength, and postural balance in evaluation of team sports interventions.

A number of health projects and campaigns have been initiated to address the issues associated with CVDs and NCDs, and to educate children about health, hygiene and the importance of physical activity. ${ }^{1}$ The Fédération Internationale de Football Association (FIFA) developed a program using football-based exercises to educate children about health, hygiene, and contamination, and to introduce regular physical activity in order for children to gain from the benefits of football practice. ${ }^{1,17,18}$

In 2015, Denmark was the first country in Europe to implement the "FIFA 11 for Health" program. The program was modified to meet the health demands of the western world, with a primary focus on reducing the risk of developing NCDs. ${ }^{13,17}$ The modifications in the physical section of the program were based on studies of football-based exercises showing that 6 - to 16 -week interventions involving two weekly sessions, lasting 30-60 minutes, of football exercises and $3 \mathrm{v} 3$ games, improved the physical health of children and adults. ${ }^{19-21}$ The modifications in the education section were focused on the themes of physical activity, nutrition, hygiene, and alcohol and tobacco consumption. The education also covered wellbeing in school, respect and a positive mindset. ${ }^{13}$

The "FIFA 11 for Health" in Europe protocol consists of $2 \times 45$-minutes interactive football sessions per week over 11 weeks, with the two weekly 45 -minutes sessions carried out at least 2 days apart. The first session is deemed "Play
Football" and teaches football skills, while the second session is called "Play Fair" and emphasizes health education through active football training. ${ }^{1}$ Both sessions include smallsided games, which aims to be the main physical stimulus of the intervention. The original European "FIFA 11 for Health" initiative, implemented in Denmark, demonstrated improved cardiovascular and metabolic health profile. ${ }^{13}$ Furthermore, the intervention markedly increased the children's health knowledge. ${ }^{17}$ In support of this, initiatives in Africa and Latin American also significantly increased health knowledge. However, the physical effects of the program were not evaluated in these regions. ${ }^{1,22,23}$ It is, however, unknown how children in a small-scale society will respond to the "FIFA 11 for Health" program.

The aim of this study was to examine the effect of introducing the "FIFA 11 for Health" in Europe program in schools in the Faroe Islands, a European small-scale society in the middle of the North Atlantic Ocean, on blood pressure, body composition, and fitness. We hypothesized that the intervention would promote physical health and fitness profile irrespective of gender.

Please click on this video link to hear more about the study.

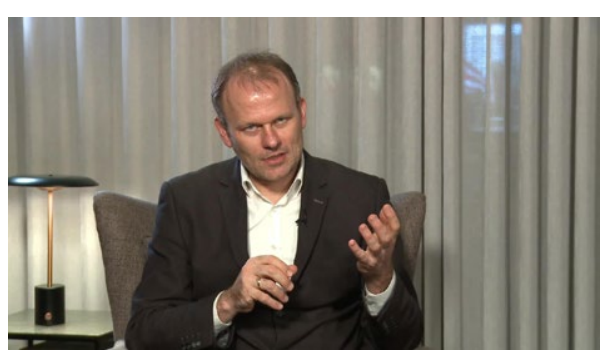

\section{$2 \mid$ METHODS}

\section{1 | Participants}

Fourteen schools in the Faroe Islands were contacted by the researchers based on the inclusion criterion of having at least one fifth-grade class with $>15$ students. Due to logistical challenges, two schools were excluded and 12 schools agreed to participate. Of the participating schools, six were located in the central region (the capital), four in the northern countryside and two in the western countryside. The trial was cluster-randomized, with each school representing a cluster, and block randomization was performed to obtain at least one representative from the central region and the countryside in the intervention (IG) and control (CG) groups, respectively. IG consisted of nine schools; five from the capital region, two from the northern countryside and two from the western countryside. The remaining schools, one from the capital region and two from the countryside, comprised CG. 23 classes consisting of 15-25 students aged 10-12 years participated. Altogether, 491 children were eligible for the study (252 
boys, 239 girls) and 392 individuals (203 boys, 189 girls) completed both pre- and post-testing (see study flowchart, Figure 1). Thirty-three of the 392 children did not complete the full test battery, but they completed both pre- and posttesting in the partial tests. These children are included in the results (Table 1). Written consent was obtained from both parents/guardians after they had received written and verbal information about the study according to the Declaration of Helsinki. The study was approved by the ethical committee of the Faroe Islands.

\section{2 | Design}

The intervention period lasted from January to June 2017. The duration of the intervention was 13 weeks; weeks 0-12. In week 0 , IG and CG completed the pre-tests. In weeks 1-11, IG performed the "FIFA 11 for Health" in Europe program (two 45-minutes sessions per week). The intervention sessions were conducted during normal school-time. The individual schools decided in which lessons (eg, math or english) the two weekly intervention sessions were performed (not in the weekly PE sessions, which were maintained as normal). CG continued their normal curriculum during the intervention period. Thus, both IG and CG continued to take their normal PE classes during the intervention. In week 12, posttesting was carried out for both IG and CG. Pre- and posttesting were identical and were conducted by the same test leader at the same time of day. Prior to the start of the study period, two teachers from each class took part in a two-day "FIFA 11 for Health" instructor course and received a diploma and a teaching manual containing information about

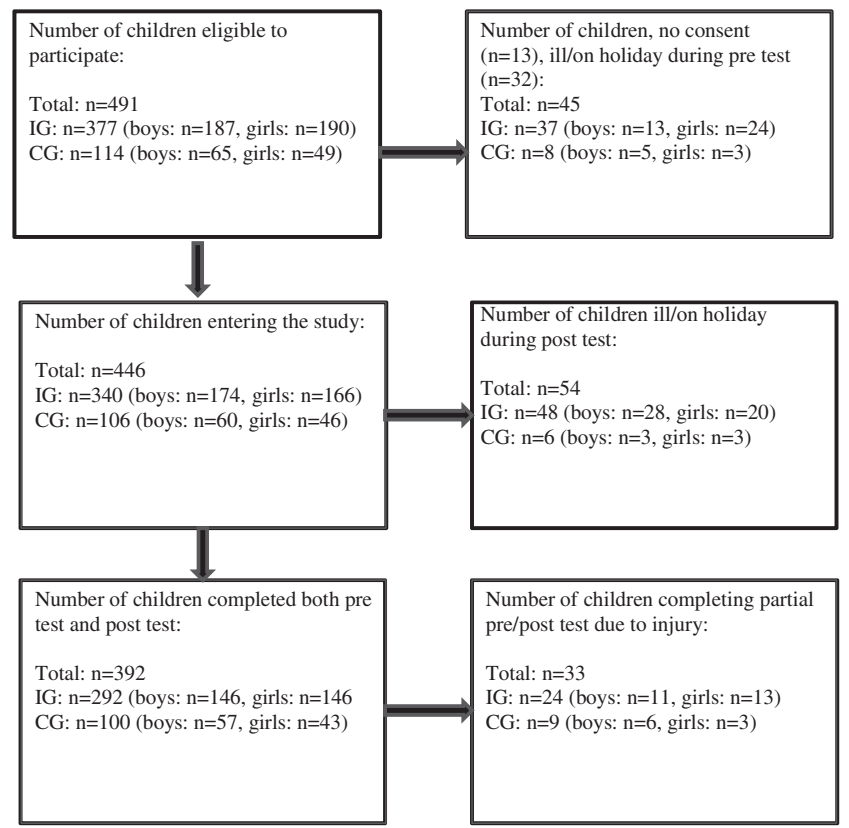

F I G U RE 1 Study flow chart. IG, intervention group; CG, control group
TA B LE 1 Subject characteristics

\begin{tabular}{|lcc|} 
& IG $(\mathbf{n}=\mathbf{2 9 2})$ & CG $(\mathbf{n}=\mathbf{1 0 0})$ \\
\hline Age $(\mathrm{y})$ & $11.1 \pm 0.3$ & $11.1 \pm 0.3$ \\
Height $(\mathrm{cm})$ & $150.6 \pm 6.9$ & $149.0 \pm 6.7$ \\
\hline Weight $(\mathrm{kg})$ & $44.2 \pm 9.4$ & $42.4 \pm 10.2$ \\
\hline Boys $(\%)$ & 50 & 57 \\
\hline Girls $(\%)$ & 50 & 43 \\
\hline
\end{tabular}

Data are presented as means \pm SD (except boys/girls ratio).

the program and detailed descriptions of each session as well as information sheets and assignments.

\section{3 | "FIFA 11 for Health" in Europe}

The "FIFA 11 for Health" program is an 11-week education program for children aged 10-12 years based on football practice and health education. ${ }^{13,17}$ In this study, the aim of the program was to incorporate physical activity in the Faroese public education system and to improve physical fitness and general health knowledge. The program lasted 11 weeks, with two weekly sessions $(2 \times 45$ minutes). The first session of a week, called "Play Football," used football-based games and activities to teach the children football skills, teamwork, and respect. The second session of a week, called "Play Fair," taught the children about physical health through footballrelated activities as an alternative to chalkboard teaching. Small-sided games $(3 \mathrm{v} 3,4 \mathrm{v} 4)$ were included in every session, and aimed to be the main physical stimulus, based on previous research. ${ }^{24}$

\subsection{Test battery}

The test protocol consisted of measurements of body composition (height, weight, body fat percentage), blood pressure and resting heart rate, postural balance, horizontal jumping performance, and Yo-Yo intermittent recovery children's test (YYIR1C) performance (see Ørntoft et al). ${ }^{13}$ All tests were carried out on the same day in the same order. Firstly, the participants were divided into groups of 6-7, one group starting with body composition measurements, the balance test and the jumping test, and the other group with blood pressure measurements. After completing one station, the groups rotated so that all participants performed all tests. Lastly, the YYIR1C test was performed for the entire class at the same time. The participants were instructed to refrain from strenuous exercise the day prior to the experimental testing.

\section{5 | Body composition}

Body height was assessed with a precision of $0.1 \mathrm{~cm}$ transportable altimeter (Tanita Leicester Transportable altimeter, 
Amsterdam, Netherlands). The participants stood barefoot with heels against the wall looking straight forward. Body weight, fat percentage, and lean body mass were measured with an InBody 230 multi-frequency body composition analyser (Biospace, California, USA) as described by Karelis et al. ${ }^{5}$ Body composition measurements were performed in the morning (08.00-09.00 o'clock) after a light breakfast. The participants were weighed barefoot wearing light clothes. The data output, as calculated by an algorithm, included fat mass ( $\mathrm{kg})$, body fat (\%), and lean body mass $(\mathrm{kg})$. The InBody technology has been validated with dual-energy $\mathrm{X}$-ray absorptiometry (DXA) on primary schoolchildren with interclass correlation coefficients (ICC) for fat percentage and lean mass of 0.94-0.99, and on adults with ICCs of $0.98-0.99 .^{5,13}$

\section{6 | Blood pressure and resting heart rate}

The participants rested on a soft mat in a quiet and dark room for 15-20 minutes before assessment, with a teacher or test leader present to avoid noise and disturbances. Systolic blood pressure (SBP), diastolic blood pressure (DBP), and resting heart rate (RHR) were measured according to standard procedures using an automatic BP monitor (HEM-709; OMRON, IL, USA). ${ }^{25}$ Mean arterial pressure (MAP) was calculated as 1/3 SBP + 2/3 DBP. Measurements were performed three consecutive times on the upper left arm. The average of the three measurements was used as the final score for SBP and DBP, and the lowest recording as RHR.

\section{7 | Postural balance test}

The postural balance was assessed by the use of the Standing Stork Balance Test. ${ }^{26}$ The participants placed their hands on their waist and stood on their preferred leg with the opposite foot resting on the knee of the standing leg with the knee pointing laterally from the standing leg. When the participants lifted their heel from the floor to balance on the ball of the foot, the test leader started a stop-watch. The time was stopped if the heel touched the floor, if one or both hands left the waist, or if the foot left the knee. The test was performed three consecutive times on the same leg for each participant on the floor of the classroom or gym. The participants were allowed one familiarization try on each leg prior to the test. The Standing Stork Balance Test has been proven reliable and correlates $(r=.65, P<.001)$ to more conventional balance tests, such as the Flamingo test, and is considered valid as a clinical tool to measure static balance. $^{26}$

\section{8 $\quad$ Horizontal jumping test}

Horizontal jumping performance was assessed according to Ørntoft et al. ${ }^{13} \mathrm{~A}$ tape measure was stretched out on the floor with a clear starting mark. The participants placed their feet behind the start, put their hands on their waist and adopted a squatting position for at least 2 seconds (akimbo). The participants jumped as far as possible, landing on both feet without the hands leaving the waist. The distance from the start to where the rear heel landed was recorded as the result. The participants performed two consecutive jumps, with the longest jump noted as the test result. The participants were allowed a familiarization try before the test, as previously described. ${ }^{13}$ The jumping test was performed immediately after the postural balance test.

\section{9 | Yo-Yo intermittent recovery children's running test (YYIR1C)}

The YYIR1C test was performed indoors on a wooden floor after a fixed warm-up protocol as previously described. ${ }^{27-29}$ Two markers were placed at each end of a 16-m running track. The participants performed running intervals of $2 \times 16 \mathrm{~m}$ at a speed dictated by a beeping signal, separated by a recovery

T A B L E 2 Resting blood pressure and heart rate before (pre) and after (post) the 11-week study period for the Intervention group (IG) and the Control group (CG)

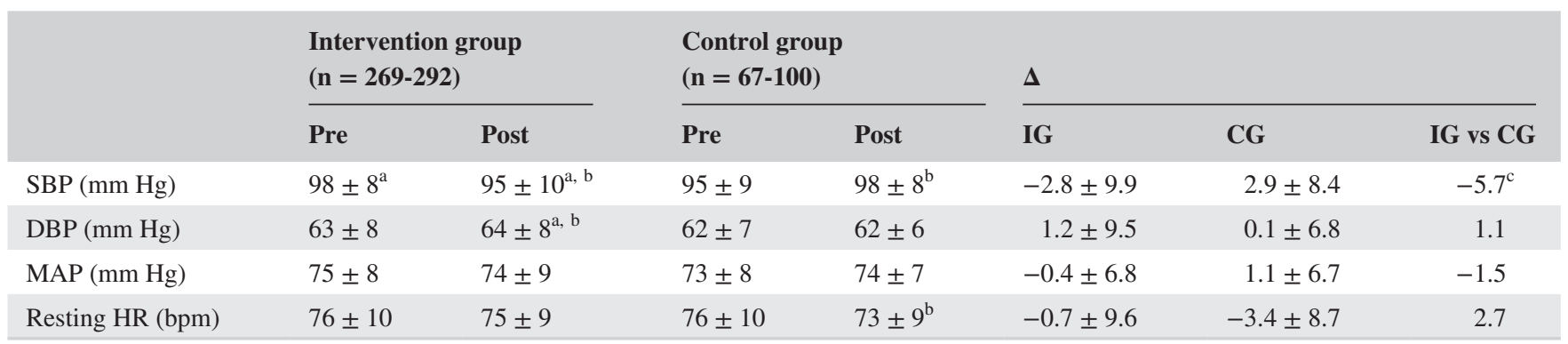

Data are presented as means \pm SD. CG, control group; IG, intervention group; SBP, systolic blood pressure; DBP, diastolic blood pressure; MAP, mean arterial pressure; HR, heart rate.

${ }^{a}$ Significantly different from control at the same measuring moment.

bignificant within-group difference.

${ }^{\mathrm{c}}$ Significant between-group difference. 


\begin{tabular}{|c|c|c|c|}
\hline Week & $\begin{array}{l}\text { Session 1: "Play } \\
\text { football" activity }\end{array}$ & $\begin{array}{l}\text { Session 2: "Play fair" } \\
\text { health topic }\end{array}$ & Issues addressed in the sessions \\
\hline 1 & Warming up & Play football & Prepare for exercise and sport \\
\hline 2 & Passing & Respect others & $\begin{array}{l}\text { Respect and help others and } \\
\text { avoid bullying }\end{array}$ \\
\hline 3 & Goalkeeping & Eat a balanced diet & Eat a full range of food types \\
\hline 4 & Dribbling & $\begin{array}{l}\text { Avoid drugs, alcohol } \\
\text { and cigarettes }\end{array}$ & $\begin{array}{l}\text { Avoid developing unhealthy } \\
\text { addictions }\end{array}$ \\
\hline 5 & Shielding & Be active & $\begin{array}{l}\text { Walk, cycle, use the stairs in } \\
\text { daily life }\end{array}$ \\
\hline 6 & Controlling & Control your weight & Control the quantity of food eaten \\
\hline 7 & Defending & Wash your hands & Develop good hygiene practices \\
\hline 8 & Building fitness & Keep fit & $\begin{array}{l}\text { Undertake sufficient vigorous } \\
\text { exercise }\end{array}$ \\
\hline 9 & Trapping & Drink water & Drink water and skimmed milk \\
\hline 10 & Shooting & Think positively & $\begin{array}{l}\text { Make friends and have a positive } \\
\text { body image }\end{array}$ \\
\hline 11 & Team working & Fair play & $\begin{array}{l}\text { Review all health issues } \\
\text { discussed in sessions } 1-10\end{array}$ \\
\hline
\end{tabular}

TA B LE 3 Overview of the 22 "FIFA

11 for Health" in Europe sessions

[Correction added August 2018, after original online publication: 'Session 1' changed to 'Session 2' in third column heading] period of 10 seconds in which the participants jogged around a marker placed $4 \mathrm{~m}$ behind the start and back to the start (see Ahler et al). ${ }^{29}$ As the test progressed, the speed increased. The children ended the test when they were unable to keep up with the beeping signals and the result was noted according to normal procedures for Yo-Yo tests. ${ }^{30}$ The test continued until all children failed to maintain the required pace. The test duration ranged from 2 to 12 minutes. The YYIR1C test has been demonstrated to have a moderate reproducibility $(\mathrm{CV}=13 \%)^{31}$

\subsection{0 | Statistics}

Data are presented as means $( \pm \mathrm{SD})$ unless otherwise stated. Change scores were calculated as the difference between pre and post measurements. A two-factor mixed ANOVA design with the between factor "group" (IG vs CG) and repeated factor "condition" (pre-training vs post-training) was used to analyze all data, except the gender effect. The gender effects were analyzed with a three-factor mixed model ANOVA (IG v CG*pre $\mathrm{v}$ post*boys $\mathrm{v}$ girls). When significant interactions or main effects were detected, data were subsequently analyzed using Bonferroni post hoc $t$ tests. Significance was accepted at $P<.05$.

\section{3 | RESULTS}

\section{1 | Resting blood pressure and heart rate}

At baseline, SBP was higher $(P<.05)$ in IG than in CG (Table 2). SBP decreased $(P<.05) 2.8 \mathrm{~mm} \mathrm{Hg}$ in IG, while there was an increase $(P<.05)$ in $\mathrm{CG}$, with a $5.7 \mathrm{~mm} \mathrm{Hg}$ greater (group-condition interaction) change score in IG compared to CG (Table 2). No significant change was observed in DBP or MAP for either IG or CG. Resting HR decreased $(P<.05)$ in $C G$ with no change in IG, and no significant group-condition interaction.

\section{2 | Body composition}

At baseline, body height and LBM were higher $(P<.05)$ in IG than in CG (Table 3). Body height increased more $(P<.05$; group-condition interaction $)$ in IG than in $\mathrm{CG}$ during the intervention period. LBM increased $(P<.05)$ in IG and CG during the intervention, but with a $0.4 \mathrm{~kg}$ greater $(P<.05$; group-condition interaction $)$ change in IG compared to GC (Table 4$)$. Total body mass increased $(P<.05)$ in both groups, but with a tendency $(P=.06)$ for greater change score $(1.0 \mathrm{~kg} P<.05)$ in IG than in CG (Table 4). BMI increased $(P<.05)$ in both IG and CG, with no between-group differences. Body fat decreased $(P<.05)$ in IG only, but the decrease was not significantly different from CG (Table 4).

\section{3 | Physical performance}

At baseline, horizontal jumping and postural balance performance were higher $(P<.05)$ in CG than in IG (Table 5). Postural balance performance increased $(P<.05)$ by $6.8 \%$ in IG and decreased $(P<.05)$ in $\mathrm{CG}$, with a 1.5 seconds between-group difference $(P<.05$; group-condition interaction) (Table 2). Horizontal jump performance was 
T A B L E 4 Anthrophometrics and body composition before (pre) and after (post) the 11-week study period for the intervention group (IG) and the control group (CG)

\begin{tabular}{|c|c|c|c|c|c|c|c|}
\hline & \multicolumn{2}{|c|}{ Intervention $(n=292)$} & \multicolumn{2}{|c|}{ Control $(n=100)$} & \multicolumn{3}{|l|}{$\Delta$} \\
\hline Height (cm) & $150.6 \pm 6.9^{\mathrm{a}}$ & $152.7 \pm 7.6^{\mathrm{a}}$ & $149.0 \pm 6.7$ & $150.0 \pm 6.9^{b}$ & $2.1 \pm 1.3$ & $1.0 \pm 1.3$ & $1.1^{\mathrm{c}}$ \\
\hline Weight (kg) & $44.2 \pm 9.4$ & $46.2 \pm 10.8^{\mathrm{a}, \mathrm{b}}$ & $42.4 \pm 10.2$ & $43.5 \pm 10.6^{b}$ & $2.0 \pm 6.2$ & $1.1 \pm 2.3$ & 0.9 \\
\hline $\mathrm{BMI}\left(\mathrm{kg} / \mathrm{m}^{2}\right)$ & $19.3 \pm 3.2$ & $19.7 \pm 4.1^{\mathrm{b}}$ & $18.9 \pm 3.5$ & $19.2 \pm 3.6^{\mathrm{b}}$ & $0.4 \pm 2.9$ & $0.3 \pm 1.1$ & 0.1 \\
\hline Body fat (\%) & $23.1 \pm 8.4$ & $22.5 \pm 8.3^{\mathrm{b}}$ & $22.6 \pm 8.5$ & $22.2 \pm 8.6$ & $-0.6 \pm 3.3$ & $-0.3 \pm 4.8$ & -0.3 \\
\hline
\end{tabular}

Data are presented as means \pm SD. CG, control group; IG, intervention group; BMI, body mass index.

${ }^{\text {a }}$ Significantly different from control at the same measuring moment.

${ }^{\mathrm{b}}$ Significant within-group difference.

${ }^{\mathrm{c}}$ Significant between-group difference.

T A B L E 5 Horizontal jump, Standing Stork postural balance test and Yo-Yo IR1C running distance before (pre) and after (post) the 11-week study period for the intervention group (IG) and the control group (CG)

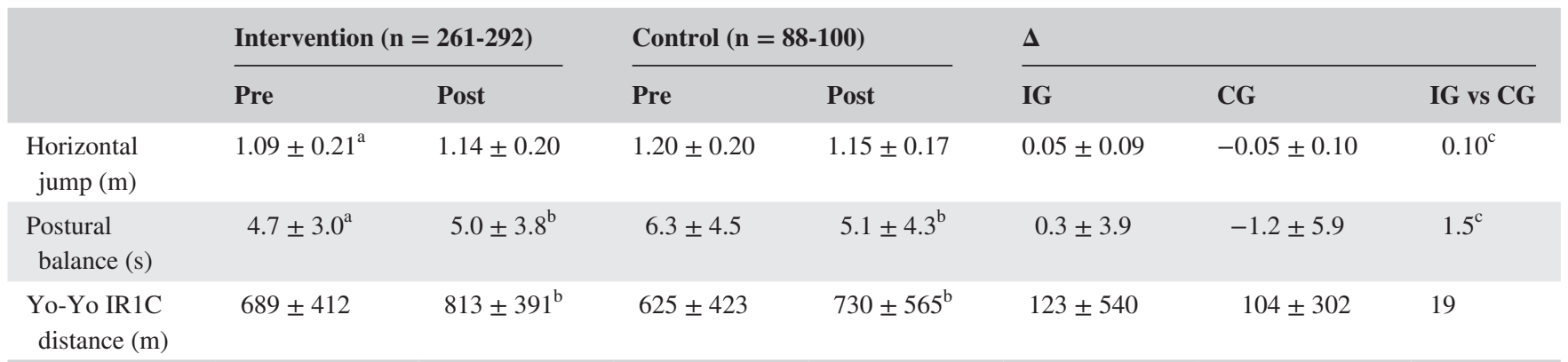

Data are presented as means $\pm \mathrm{SD}$. CG, control group; IG, intervention group; Yo-Yo IR1C, Yo-Yo intermittent recovery level 1 children's running test.

${ }^{a}$ Significantly different from control at the same measuring moment.

${ }^{\mathrm{b}}$ Significant within-group difference.

${ }^{\mathrm{c}}$ Significant between-group difference.

improved $(P<.05)$ by $10 \mathrm{~cm}$ in IG compared to $\mathrm{CG}$ (Table 2). Both groups improved their Yo-Yo IR1C test performance $(P<.05)$, with no between-group difference (Table 5).

\section{4 | Gender-specific effects}

Baseline performance in horizontal jumping and postural balance was higher $(P<.05)$ in CG girls than in IG girls (Table 6). Height, total body weight, and LBM increased more $(P<.05$; gender-group-condition interaction) in IG girls than in CG girls. Furthermore, SBP decreased more $(P<.05 ;$ gender-group-condition interaction) in IG girls than in CG girls $(-5.2 \mathrm{~mm} \mathrm{Hg}$; Table 6). Horizontal jumping performance $(13 \mathrm{~cm})$ and postural balance $(2.1 \mathrm{~s})$ also increased more $(P<.05$; gendergroup-condition) in IG girls than in CG girls (Table 6). Finally, Yo-Yo IR1C performance increased $(P<.05)$ in both groups of girls, with no significant between-group difference (Table 6).

In boys, baseline LBM and MAP were higher $(P<.05)$ in IG than in CG, and baseline performance in horizontal jumping and postural balance was higher $(P<.05)$ in CG than in IG boys (Table 6$)$. For the boys, height increased more $(P<.05$; gender-group-condition) in IG than in CG. Body fat percentage decreased $(P<.05)$ in the IG-boys, but there was no significant between-group (Table 6) difference. LBM increased $(P<.05)$ in both groups of boys, with no significant betweengroup differences (Table 6). SBP decreased $(P<.05)$ in IG and increased $(P<.05)$ in $\mathrm{CG}$ with a between-group change $(P<.05$; gender-group-condition) of $-6.3 \mathrm{~mm} \mathrm{Hg}$ (Table 6$)$. Yo-Yo IR1C performance increased $(P<.05)$ in both groups of boys, with no significant between-group differences (Table 6).

LBM, BMI, and body mass increased more $(P<.05$; gendergroup-condition) during the intervention in girls than in boys (Table 6). No other gender-specific differences were observed. 
T A B L E 6 Body composition, resting blood pressure, heart rate and physical fitness tests; girls (IG vs CG) and boys (IG vs CG)

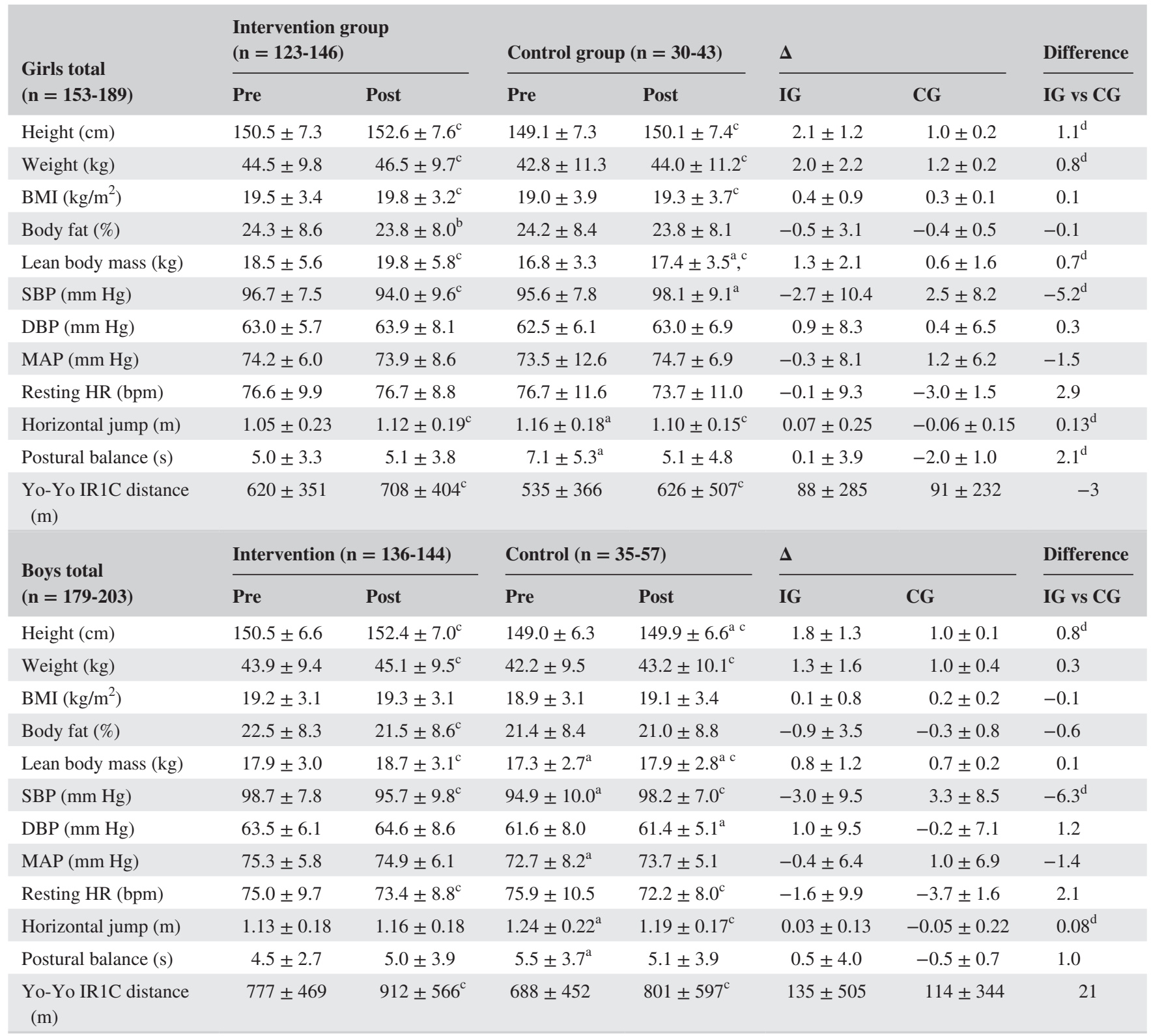

Data are presented as means $\pm \mathrm{SD}$. Only data from intervention group is included. BMI, body mass index; SBP, systolic blood pressure; DBP, diastolic blood pressure; MAP, mean arterial pressure; HR, heart rate; Yo-Yo IR1C, Yo-Yo intermittent recovery level 1 children's running test; Postural balance, Standing Stork balance test; Horizontal jump performance.

${ }^{\text {a }}$ Significantly different from intervention at the same measuring moment.

${ }^{\mathrm{b}}$ Significantly different from boys at the same measuring moment.

'Significant within-group difference.

${ }^{\mathrm{d}}$ Significant between-group difference.

\section{4 | DISCUSSION}

The principal findings of the present study were that the "FIFA 11 for Health" for Europe program lowered SBP, improved postural balance and jump performance and increased lean body mass. No changes were observed in resting heart rate. Intermittent running performance increased significantly in both groups during the intervention. Finally, the study showed some gender-specific adaptations to the intervention.

Systolic blood pressure decreased by $\sim 6 \mathrm{~mm} \mathrm{Hg}$ in IG compared to $\mathrm{CG}$, whereas no changes were observed in DBP, MAP, and RHR. This decrease in SBP in the present study is similar to or even larger than reported in other comparable training studies for children aged 9-13 using intervention periods of 10 weeks to 2 years, for example, -1 to $-4 \mathrm{~mm} \mathrm{Hg} .{ }^{13,20,32}$ The decrease in SBP was evident in both 
genders, which beneficial effects on blood pressure in normotensive boys and girls. A reduction in SBP of $6 \mathrm{~mm} \mathrm{Hg}$ is considered clinically relevant in adults, with an estimated $13 \%$ reduction in cardiovascular mortality and morbidity for every $5 \mathrm{~mm} \mathrm{Hg}$ reduction in SBP. ${ }^{25}$ Despite a lack of similar risk assessments in children, this response, if sustained into adulthood, has great beneficial cardiovascular health effects. In the present study, we did not measure physiological parameters of importance for SBP except body fat percentage, but previous RCTs applying small-sided football training to adults have demonstrated decreased arterial stiffness, improved blood lipid profile, increased muscle capillarization as well as lowered body fat mass. ${ }^{19-21,33-35}$ Together, it appears that this type of short-term football interventions are effective in improving the cardiovascular health profile for children as well as adults.

Postural balance also improved in IG compared to CG. This effect was hypothesized prior to the study based on other studies examining postural balance after football-based training interventions lasting $12-14$ weeks $^{36,37}$ and 16 months. ${ }^{34}$ The adaptive changes in the somatosensory system and increased strength in lower-limb bone and muscle may have led to the improved postural balance. ${ }^{36,38}$ This was supported by an increase in horizontal jump performance of $10 \mathrm{~cm}$ in IG compared to CG. Other comparable intervention studies lasting 11-12 weeks ${ }^{13,39}$ found no significant effects on jump performance. In contrast, a 6-month intervention ${ }^{15}$ demonstrated increases in jumping distance, and a 10-month intervention comprising $3 \times 40$ minutes per week of small-sided games for 8- to 10-year-old children have shown an increase in both postural balance and jump test performance. ${ }^{12}$

In the present study, there was no between-group change in either body fat percentage or BMI between IG and CG after the intervention period. These findings are in accordance with other studies on school-based activity with interventions ranging from 6 weeks to 6 years. ${ }^{20,32,40,41}$ In these studies, it was proposed that the exercise intensity is of greater importance than the total amount of physical activity. A lack of intensity in the sessions can, therefore, be suggested to have played a role in the unchanged body fat content. However, the difference in sexual maturity and growth is a major factor in studies involving prepubertal children. Thus, the lack of changes may also be associated with the natural growth and maturity process of the children. Height, total body weight, and LBM increased significantly in both IG and CG, but with a greater change score in IG for height and LBM. Thus, the larger increase in height may partly be associated with an advanced maturity in the children in the IG group. However, the increase in LBM could additionally indicate muscle hypertrophy as a result of additional exercise. ${ }^{12,35}$ The girls in IG had a significantly larger increase in LBM compared to the IG-boys, which may be associated with an accelerated biological maturity in girls compared to boys. However, these gender differences were not present in CG. Furthermore, body fat percentage in the IG-boys decreased, whereas it was unchanged in the IG-girls. According to questionnaires (data not shown) that the participants were asked to complete prior to the intervention, $51 \%$ of the boys and $49 \%$ of the girls were physically active in their leisure-time. Thus, the superior LBM increase in girls and the greater decrease in body fat percentage in boys are likely to be associated with advanced maturity, predominately in the girls, combined with the "FIFA 11 for Health" intervention, and not due to different responses to the physical exercise in their leisure-time.

Yo-Yo IR1C performance increased $18 \%$ in IG and $17 \%$ in CG during the intervention period, with no between-group difference. Other studies have reported similar effects of smallsided football games on Yo-Yo IR1C performance in children after 6 weeks ${ }^{42}$ and 10 months, ${ }^{12}$ but in contrast the present study showed no change compared to the control group as in studies by Bendiksen et $\mathrm{al}^{42}$ and Larsen et $\mathrm{al}^{12}$ Studies have shown that high-intensity football training is associated with aerobic intermittent high-intensity exercise capacity, and that high-intensity training can be efficient at improving aerobic exercise in adolescents and adults. ${ }^{31,43,44}$ In the present study, the exercise intensity of the football training sessions was not assessed. Thus, we cannot rule out that the exercise intensity was too low to result in major improvements in the endurance capacity of the children. A limitation of the study in relation to the YYIR1C test is the lack of a familiarization trial prior to baseline testing, albeit other studies have shown that no familiarization is needed in this test. ${ }^{29}$

There is limited research on the physical health status of Faroese children. The Faroe Islands have only 50000 inhabitants and are geographically isolated in the middle of the North Atlantic Ocean. For the first time, a vast majority of the children aged 10-12 years in a small-scale society have been studied in relation to health and fitness profile, as well as the impact of an exercise and health-teaching intervention performed in a school setting. The intervention was added to the PE sessions and based on the novel results of the present investigation, the "FIFA 11 for Health" program is an effective way of promoting health in respect of three major risk factors for developing CVD in this type of society. However, future research should aim to provide data on diet and exercise intensity to give more accurate and detailed results.

One limitation of the study was that nine schools were included as intervention schools and only three as control schools. Even though the randomization procedure was carried out as block randomization, making sure that one control group was included from each of the three geographical clusters, some baseline differences were observed between the intervention group and the control group. 
In conclusion, the results of the present study confirmed the hypothesis that the "FIFA 11 for Health" program, based on football training and $3 \mathrm{v} 3$ games, would improve fitness and physical health of children aged 10-12 years. Thus, this type of high-intensity interval exercise training is suggested to be incorporation in the school curriculum in all classes to improve physical health and reduce the risk of developing NCDs.

\section{1 | Perspectives}

The present study emphasizes that "FIFA 11 for Health" in Europe can be used as a tool to improve physical health profile of children aged 10-12 years in a small-scale islands society. Thus, team sports organized as small-sided high-intensity games in combination with health education can be included in the school curriculum to improve fitness and health profile and to contribute the prevention of non-communicable diseases. The "FIFA 11 for Health" in Europe sessions are conducted by schoolteachers and the sessions were easily incorporated in the Faroese school system. Moreover, the structure of the sessions requires minimal use of resources and space and allows sessions to be conducted outside or inside in small areas, therefore it would be easy to implement in other small-scale countries.

\section{ACKNOWLEDGEMENTS}

The authors would like to thank the children, teachers, and schools for their committed participation. Special thanks go to Askur Holm Magnason, Ólavur Jøkladal, Sólfríð Skoradal and Virgar Hvidbro. Funding was obtained from the Danish Football Association (Dansk Boldspil-Union, DBU), the Faroese Board of Public Health and the Faroese Football Federation, as well as from the FIFA Medical Assessment and Research Centre (F-MARC).

\section{ORCID}

P. Krustrup (D) http://orcid.org/0000-0002-1461-9838

\section{REFERENCES}

1. Fuller CW, Junge A, Dorasami C, DeCelles J, Dvorak J. " 11 for Health", a football-based health education programme for children: a two-cohort study in Mauritius and Zimbabwe. Br J Sports Med. 2011;45:612-618.

2. Lette M, Bemelmans WJE, Breda J, Slobbe LCJ, Dias J, Boshuizen HC. Health care costs attributable to overweight calculated in a standardized way for three European countries. Eur J Health Econ. 2016;17:61-69.

3. Gungor KN. Overweight and obesity in children and adolescents. J Clin Res Pediatr Endocrinol. 2014;6:129-143.
4. Gurnani M, Birken C, Hamilton J. Childhood obesity: causes, consequences, and management. Pediatr Clin North Am. 2015;62:821-840.

5. Søltoft F, Hammer F, Kragh N. The association of body mass index and health-related quality of life in the general population: data from the 2003 Health Survey of England Health. Qual Life Res. 2009;18:1293-1299.

6. Nadeau KJ, Maahs DM, Eckel RH. Childhood obesity and cardiovascular disease: links and prevention strategies. Nat Rev Cardiol. 2011;8:513-525.

7. Serdula MK, Ivery D, Coates RJ, Freedman DS, Williamson DF, Byers T. Do obese children become obese adults? A review of literature. Prev Med. 1993;22:167-177.

8. Tishukaj F, Shalaj I, Gjaka M, et al. Physical fitness and anthropometric characteristics among adolescents living in urban or rural areas of Kosovo. BMC Public Health. 2017;17:711.

9. Andersen LB, Harro M, Sardinha LB, et al. Physical activity and clustered cardiovascular risk in children: a crosssectional study (The European Youth Heart Study). Lancet. 2006;368:299-304.

10. Dvorak J, Fuller CW, Junge A. Planning and implementing a nationwide football-based health-education programme. Br J Sports Med. 2011;46:6-10.

11. Barriguete Melendez J, Dvorak J, Córdova Villalobos J, et al FIFA 11 for Health in Mexico: a school-based intervention for the prevention of obesity and non-communicable diseases. $\mathrm{Br} J$ Sports Med. 2013;48:940-941.

12. Larsen MN, Nielsen CM, Helge EW, et al. Positive effects on bone mineralisation and muscular fitness after 10 months of intense school-based physical training for children aged 8-10 years: the FIT FIRST randomised controlled trial. Br J Sports Med. 2018;54:254-260.

13. Ørntoft C, Fuller C, Larsen MN, Bangsbo J, Dvorak J, Krustrup P. "FIFA 11 for Health "for Europe. II: effect on health markers and physical fitness in Danish schoolchildren aged 10-12 years. $\mathrm{Br} J$ Sports Med. 2016;50:1394-1399.

14. Andersen LB, Riddoch C, Kriemler S, Hills A. Physical activity and cardiovascular risk factors in children. Br J Sports Med. 2011;45:871-876.

15. Faude O, Kerper O, Multhaupt M, et al. Football to tackle overweight children. Scand J Med Sci Sports. 2010;20(Suppl 1):103-110

16. Seabra AC, Seabra AF, Brito J, et al. Effects of a 5-month football program on perceived psychological status and body composition of overweight boys. Scand J Med Sci Sports. 2014;24(Suppl 1):10-16.

17. Fuller CW, Ørntoft C, Larsen MN, et al. 'FIFA 11 for Health' for Europe. 1: effect on health knowledge and well-being of 10- to 12-year-old Danish school children. Br J Sports Med. 2017;51:1483-1488.

18. Dvorak J, Fuller CW, Junge A. Planning and implementing a nationwide football-based health-education programme. Br J Sports Med. 2012;46:6-10.

19. Krustrup P, Nielsen JJ, Krustrup BR, et al. Recreational soccer is an effective health-promoting activity for untrained men. $\mathrm{Br} J$ Sports Med. 2009;43:825-831.

20. Krustrup P, Hansen PR, Nielsen CM, et al. Structural and functional cardiac adaptations to a 10-week school-based football intervention for 9-10-year-old children. Scand J Med Sci Sports. 2014;24:4-9. 
21. Krustrup P, Bangsbo J. Recreational football is effective in the treatment of non-communicable diseases. $\mathrm{Br} J$ Sports Med. 2015;49:1426-1427.

22. Fuller CW, Junge A, DeCelles J, Donald J, Jankelowitz R, Dvorak J. "Football for Health" - a football-based health-promotion programme for children in South Africa: a parallel cohort study. $\mathrm{Br} \mathrm{J}$ Sports Med. 2010;44:546-554.

23. Fuller C, Thiele E, Flores M, Junge A, Netto D, Dvorak J. A successful nationwide implementation of the "FIFA 11 for Health" programme in Brazilian elementary schools. $\mathrm{Br} J$ Sports Med. 2015;49:623-629.

24. Randers MB, Nybo L, Petersen J, et al. Activity profile and physiological response to football training for untrained males and females, elderly and youngsters: influence of the number of players. Scand J Med Sci Sports. 2010;20(Suppl 1):14-23.

25. Krustrup P, Randers MB, Andersen LJ, Jackman SR, Bangsbo J, Hansen PR. Soccer improves fitness and attenuates cardiovascular risk factors in hypertensive men. Med Sci Sports Exerc. 2013;45:553-560.

26. Panta K, Arulsingh W, Raj JO, Sinha M, Rahman M. A study to associate the Flamingo Test and the Stork Test in measuring static balance on healthy adults. Foot Ankle Online J. 2015;8:4.

27. Bendiksen M, Bischoff R, Randers MB, et al. The Copenhagen Soccer Test: physiological response and fatigue development. Med Sci Sports Exerc. 2012;44:1595-1603.

28. Bendiksen M, Ahler T, Clausen H, Wedderkopp N, Krustrup P. The use of Yo-Yo intermittent recovery level 1 and Andersen testing for fitness and maximal heart rate assessments of 6-10-year-old school children. J Strength Cond Res. 2013;27:1583-1590.

29. Ahler T, Bendiksen M, Krustrup P, Wedderkopp N. Aerobic fitness testing in 6- to 9-year-old children: reliability and validity of a modified Yo-Yo IR1 test and the Andersen test. Eur J Appl Physiol. 2012;112:871-876.

30. Bangsbo J, Mohr M. Fitness Testing in Football. Copenhagen, Denmark: Bangsbosport; 2012. 130.

31. Póvoas SC, Castagna C, Soares JM, Silva PM, Lopes MV, Krustrup P. Reliability and validity of Yo-Yo tests in 9- to 16year-old football players and matched non-sports active schoolboys. Eur J Sport Sci. 2016;16:755-763.

32. Cesa C, Sbruzzi G, Ribeiro RA, et al. Physical activity and cardiovascular risk factors in children: meta-analysis of randomized clinical trials. Prev Med. 2014;69:54-62.

33. Karelis AD, Chamberland G, Aubertin-Leheudre M, Duval C. Validation of a portable bioelectrical impedance analyzer for the assessment of body composition. Appl Physiol Nutr Metab. 2013;38:27-32.

34. Krustrup P, Aagaard P, Nybo L, Petersen J, Mohr M, Bangsbo J. Recreational football as a health promoting activity: a topical review. Scand J Med Sci Sports. 2010;20(Suppl 1):1-13.
35. Bangsbo J, Hansen PR, Dvorak J, Krustrup P. Recreational football for disease prevention and treatment in untrained men: a narrative review examining cardiovascular health, lipid profile, body composition, muscle strength and functional capacity. Br J Sports Med. 2015;49:568-576.

36. Jakobsen MD, Sundstrup E, Krustrup P, Aagaard P. The effect of recreational soccer training and running on postural balance in untrained men. Eur J Appl Physiol. 2011;111:521-530.

37. Elbe AM, Strahler K, Krustrup P, Wikman J, Stelter R. Experiencing flow in different types of physical activity intervention programs: three randomized studies. Scand J Med Sci Sports. 2010;20(Suppl 1):111-117.

38. Helge EW, Aagaard P, Jakobsen MD, et al. Recreational football training decreases risk factors for bone fractures in untrained premenopausal women. Scand J Med Sci Sports. 2010;20(Suppl 1):31-39.

39. Jakobsen MD, Sundstrup E, Bredsgaard M, Kjær M, Andersen LL, Krustrup P. Aagaard. Human Movement Science The effect of strength training, recreational soccer and running exercise on stretch - shortening cycle muscle performance during countermovement jumping. Hum Mov Sci. 2012;31:970-986.

40. Dobbins M, Decorby K, Robeson P, Husson H, Tirilis D. Schoolbased physical activity programs for promoting physical activity and fitness in children and adolescents aged 6-18 (Review). Cochrane Database Syst Rev. 2009;21:CD007651.

41. Mei H, Xiong Y, Xie S, et al. The impact of long-term schoolbased physical activity interventions on body mass index of primary school children - a meta-analysis of randomized controlled trials. BMC Public Health. 2016;16:205.

42. Bendiksen M, Williams CA, Hornstrup T, et al. Heart rate response and fitness effects of various types of physical education for 8- to 9-year-old schoolchildren. Eur J Sport Sci. 2014;14:861-869.

43. Hansen PR, Andersen LJ, Rebelo AN, et al. Cardiovascular effects of 3 months of football training in overweight children examined by comprehensive echocardiography: a pilot study. J Sports Sci. 2013;31:1432-1440.

44. Krustrup P, Dvorak J, Bangsbo J. Small-sided football in schools and leisure-time sport clubs improves physical fitness, health profile, well-being and learning in children. Br J Sports Med. 2016;50:1166-1167.

How to cite this article: Skoradal M-B, Purkhús E, Steinholm H, et al. "FIFA 11 for Health" for Europe in the Faroe Islands: Effects on health markers and physical fitness in 10- to 12-year-old schoolchildren. Scand J Med Sci Sports. 2018;28(Suppl. 1):8-17. https://doi.org/10.1111/sms.13209 